\title{
Effect of Mass Transport on the Electrochemical Oxidation of Alcohols Over Electrodeposited Film and Carbon-Supported Pt Electrodes
}

\author{
Vinod Kumar Puthiyapura ${ }^{1}$ - Wen-Feng Lin ${ }^{2} \cdot$ Andrea E. Russell $^{3} \cdot$ Dan J. L. Brett ${ }^{4} \cdot$ Christopher Hardacre $^{1}$
}

Published online: 19 January 2018

(C) The Author(s) 2018. This article is an open access publication

\begin{abstract}
Electrochemical oxidation of four different alcohol molecules (methanol, ethanol, $n$-butanol and 2-butanol) at electrodeposited Pt film and carbon-supported Pt catalyst film electrodes, as well as the effect of mass transport on the oxidation reaction, has been studied systematically using the rotating disk electrode (RDE) technique. It was shown that oxidation current decreased with an increase in the rotation rate $(\omega)$ for all alcohols studied over electrodeposited Pt film electrodes. In contrast, the oxidation current was found to increase with an increase in the $\omega$ for Pt/C in ethanol and $n$-butanol-containing solutions. The decrease was found to be nearly reversible for ethanol and $n$-butanol at the electrodeposited Pt film electrode ruling out the possibility of intermediate $\mathrm{CO}_{\text {ads }}$ poisoning being the sole cause of the decrease and was attributed to the formation of soluble intermediate species which diffuse away from the electrode at higher $\omega$. In contrast, an increase in the current with an increase in $\omega$ for the carbon supported catalyst may suggest that the increase in residence time of the soluble species within the catalyst layer, results in further oxidation of these species. Furthermore, the reversibility of the peak current on decreasing the $\omega$ could indicate that the surface state has not significantly changed due to the sluggish reaction kinetics of ethanol and $n$-butanol.
\end{abstract}

Keywords Direct alcohol fuel cells $\cdot$ Rotating disk electrode $(\mathrm{RDE}) \cdot$ Electro-oxidation $\cdot$ Methanol $\cdot$ Ethanol $\cdot$ Butanol . Platinum

Electronic supplementary material The online version of this article (https://doi.org/10.1007/s11244-018-0893-6) contains supplementary material, which is available to authorized users.

Wen-Feng Lin

w.lin@lboro.ac.uk

$\triangle$ Christopher Hardacre

c.hardacre@manchester.ac.uk

1 School of Chemical Engineering and Analytical Science, The University of Manchester, Manchester M13 9PL, UK

2 Department of Chemical Engineering, Loughborough University, Loughborough, Leicestershire LE1 13TU, UK

3 Department of Chemistry, University of Southampton, High Field, Southampton SO17 1BJ, UK

4 Department of Chemical Engineering, University College London (UCL), London WC1E 7JE, UK

\section{Introduction}

The electrochemical oxidation of alcohols is an important reaction in direct alcohol fuel cells (DAFCs). Due to their relatively high reactivity for electro-oxidation, methanol and ethanol have been widely studied as a fuel for DAFCs [1-3]. Recently, second-generation biofuels such as butanol have also attracted attention as alternative fuels to methanol and ethanol for the DAFCs $[4,5]$. Pt is known as the most active single metal catalyst for alcohol oxidation reaction in acidic media and has been studied extensively for methanol [6-10], ethanol [11-13] and butanol isomers [4, 5, 14-16]. The intermediates formed during the oxidation of the alcohol molecules on the Pt surfaces have been identified using various electrochemical and spectroscopic techniques such as in-situ FT-IR [17, 18] and online differential electrochemical mass spectroscopy (DEMS) [18-23]. Based on these studies, a dual path reaction mechanism (Scheme 1) has been proposed and well documented for small chain alcohol molecules [24]. 


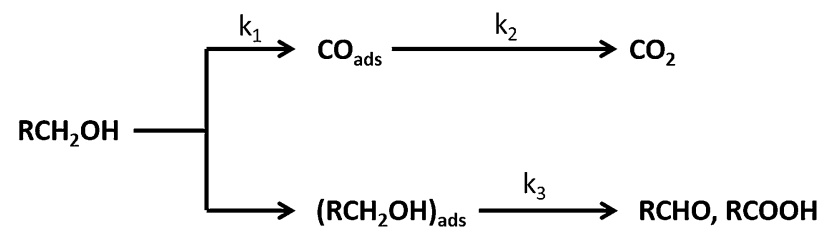

Scheme 1 The dual path mechanism of alcohol oxidation reaction [25]

Alcohol molecules have two active sites $(\mathrm{OH}$ group and $\alpha$ carbon atom) that can interact with the metal catalyst during the adsorption process [26] and they can adsorb onto the catalyst surface through either of these sites by breaking the $\mathrm{O}-\mathrm{H}$ or $\mathrm{C}-\mathrm{H}$ bond to form adsorbed intermediates before the cleavage of $\mathrm{C}-\mathrm{C}$ and/or $\mathrm{C}-\mathrm{O}$ bonds, as given in Eqs. (1) and (2) [26, 27]. This is considered as the first step in the oxidation of alcohols [28].
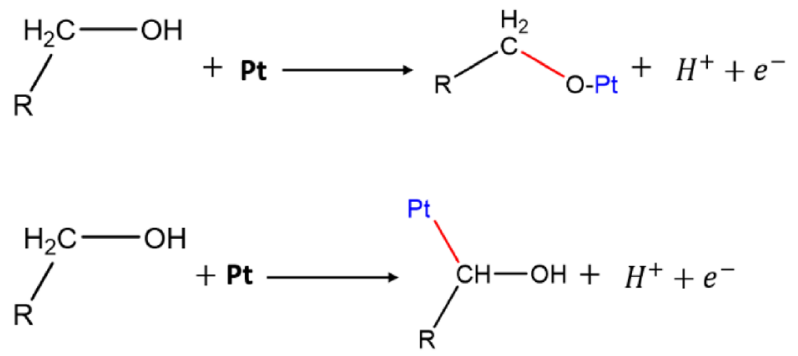

Both $\mathrm{C}$ - and O-bound adsorbed species could have a proton removed and form an aldehyde (-CHO) species. According to the dual path mechanism for primary alcohols (Scheme 1) the reaction follows two parallel pathways: (i) adsorption of alcohol to the catalyst surface and direct dehydrogenation to form $\mathrm{CO}_{\text {ads }}$ which may further oxidise to form $\mathrm{CO}_{2}$ and (ii) a series of non-adsorbing intermediate species forming partial oxidation products [29, 30]. Due to the complex reaction pathways and formation of various adsorbed intermediates, alcohol oxidation reaction is generally sluggish on Pt. With the increase in carbon chain length, the electro-oxidation reactivity of alcohols was observed to decrease on $\mathrm{Pt}$ as in the order methanol $>$ ethanol $>$ propanol $>$ butanol $[31,32]$ due to the difficulty in $\mathrm{C}-\mathrm{C}$ bond cleavage. The high overpotential requirement for the alcohol oxidation reaction and the deactivation due to $\mathrm{CO}_{\text {ads }}$ poisoning are still the major obstacles for the alcohol oxidation reaction $[33,34]$. The removal of $\mathrm{CO}_{\text {ads }}$ from the Pt surface requires an oxidant, for example, $\mathrm{OH}_{\mathrm{ads}}$, which is formed by the oxidation of water only at relatively high potentials [35].

For the methanol oxidation reaction (MOR), $\mathrm{CO}_{2}$ is formed together with significant quantities of $\mathrm{HCHO}$ and $\mathrm{HCOOH}$ on Pt [21, 29, 30, 36, 37]. $\mathrm{A} \mathrm{CO}_{2}$ generation current efficiency less than $100 \%$ indicates a parallel reaction pathway towards partial oxidation products [7, 21, 36, 38].
A DEMS study for the ethanol oxidation reaction (EOR) on Pt has shown that EOR mainly forms $\mathrm{CO}_{2}, \mathrm{CH}_{3} \mathrm{CHO}$ and $\mathrm{CH}_{3} \mathrm{COOH}[18,22,39,40]$. Mostafa et al. [22] observed a $\mathrm{CO}_{2}$ product yield of $1 \%$ in comparison to $\mathrm{CH}_{3} \mathrm{CHO}(55 \%)$ and $\mathrm{CH}_{3} \mathrm{COOH}(44 \%)$ during EOR on Pt/C. Ethane 1,1 diol [11] was also detected as a product of EOR which forms as result of hydrolysis of $\mathrm{CH}_{3} \mathrm{CHO}$.

The electrochemical activity of the electrocatalysts is usually studied under steady-state conditions in a three-electrode system. However, in a real fuel cell, the fuel is generally fed into the anode of DAFCs; i.e. the system is under non-steady state condition. It is thus important to understand the effect of fuel transport to the catalyst on its activity. The maximum oxidation current is generally limited by the formation of $\mathrm{Pt}$ oxides and not the diffusion of the alcohol [41, 42]. Thus, the alcohol oxidation current is generally not expected to increase with an increase in mass transport. Since water is present in large excess, the reaction of water to give $\mathrm{OH}_{\text {ads }}$ is also not considered to be influenced significantly by mass transport [38]. An increased flow rate of alcohol is usually found to decrease the fuel cell membrane electrode assembly (MEA) activity and this was mainly attributed to the alcohol crossover through the proton exchange membrane to the cathode side $[43,44]$. However, moderate flow rates also help in the removal of the product $\mathrm{CO}_{2}$ generated in the flow field. A slow flow rate, on the other hand, may result in depletion of the alcohol, especially at high current density [45], reducing the MEA performance. Not many reports dedicated to studying the effect of flow rate on the catalyst activity have been documented in the literature. Katayangi and Yamazaki [46] observed a decrease in $\mathrm{CO}_{2}$ production in a single ethanol fuel cell on increasing the ethanol flow rate with $\mathrm{Pt} / \mathrm{C}$ anode catalyst and attributed this to the dominant formation of acetaldehyde.

A few half-cell studies are available on the effect of mass transport upon alcohol oxidation over Pt, but these have concentrated on the utilisation of methanol as a fuel [38, 41, 42, 47-49] with very few studies using ethanol [39, 50, 51]. Most studies have reported a suppression of the extent of oxidation of methanol on Pt disk electrode with increased mass transport $[38,42]$. This has been attributed to the enhanced production of soluble species which diffuse away from the catalyst surface at the expense of $\mathrm{CO}_{2}$ production [38]. However, not all studies are in agreement. For example, Hou et al. [52] reported an increase in peak current for methanol oxidation current on increased rotation rate $(\omega)$ for smooth $\mathrm{Pt}$ in $1 \mathrm{M}$ methanol $+0.5 \mathrm{M} \mathrm{H}_{2} \mathrm{SO}_{4}$ solution. These discrepancies could be due to the different experimental conditions employed, such as scan rate, concentration, temperature, catalyst loading, electrode surface structure etc. In contrast, on carbon supported $\mathrm{Pt}$, a less significant change [42] or an increase in the current [51] with an increase in $\omega$ was reported. However, methanol 
oxidation activity is not always a good model for long chain alcohol oxidation as it does not require $\mathrm{C}-\mathrm{C}$ bond breaking.

In the study reported herein, the effects of mass transport on the electro-oxidation of higher alcohol molecules such as $n$-butanol and 2-butanol have been investigated and compared with those for methanol and ethanol using both electrodeposited Pt film and carbon supported Pt nanoparticle electrocatalysts. Also, the influence of catalyst layer thickness on the activity of Pt under increased mass transport is described in details.

\section{Experimental}

The electrochemical measurements were carried out in a standard three-electrode cell using a potentiostat (SP240, BioLogic) and Pine rotating disk electrode set up with a glassy carbon (GC) electrode of $5 \mathrm{~mm}$ diameter. $\mathrm{A} \mathrm{Ag} / \mathrm{AgCl}-3 \mathrm{M}$ $\mathrm{NaCl}$ (Basi, USA) (0.210 V vs. NHE) and a Pt mesh (Goodfellow, UK) were used as reference and counter electrode respectively. All potentials are referenced with respect to $\mathrm{Ag} / \mathrm{AgCl}-3 \mathrm{M} \mathrm{NaCl}$ unless specified otherwise. $\mathrm{N}_{2}$ gas was purged through the electrolyte solution for 15-20 min before carrying out the electrochemical analysis. The GC electrode was polished with $1,0.3$ and $0.05 \mu \mathrm{m}$ alumina powder with subsequent ultrasonication in de-ionised water before use. To prepare the electrodeposited thin film electrode, Pt was electrodeposited onto the GC electrode from $5 \mathrm{mM}$ $\mathrm{H}_{2} \mathrm{PtCl}_{6}+0.1 \mathrm{M} \mathrm{H}_{2} \mathrm{SO}_{4}$ solution at a potential of $-0.22 \mathrm{~V}$ for $15 \mathrm{~min}\left(2 \mathrm{mM} \mathrm{H}_{2} \mathrm{PtCl}_{6}+0.05 \mathrm{M} \mathrm{H}_{2} \mathrm{SO}_{4}\right.$ for $30 \mathrm{~min}$ in Figs. 1c, 2a). The loading and the thickness of the catalyst layer for electrodeposited Pt electrode is calculated using (3) and (4), where $Q$ is the charge passed during the electrodeposition assuming $4 \mathrm{e}^{-}$reduction of $\mathrm{Pt}^{4+}$ to $\mathrm{Pt}(0), \mathrm{M}$ is the molecular weight of the $\mathrm{Pt}\left(195.08 \mathrm{gmol}^{-1}\right), n$ is the number of electrons required for the deposition of one mole of $\mathrm{Pt}, F$ is the Faraday constant $\left(96,485 \mathrm{C} \mathrm{mol}^{-1}\right), \rho$ is the density of $\mathrm{Pt}$ $\left(21.45 \mathrm{~g} \mathrm{~cm}^{-3}\right)$ and $A$ is the geometric area of the glassy carbon electrode $\left(0.1963 \mathrm{~cm}^{2}\right)$ (Table 1). The morphology of the electrodeposited Pt has been described previously [5] where a 'cauliflower-like' spherical morphology was observed.

The electrode was activated in $\mathrm{N}_{2}$ saturated $0.1 \mathrm{M} \mathrm{HClO}_{4}$ solution at a potential range of -0.22 to $1.3 \mathrm{~V}$ for about $25-30$ cycles until a stable cyclic voltammogram (CV) is obtained before being tested in alcohol containing the solution. A typical CV of Pt obtained in the acidic solution is given in Fig. S1. The electrochemical active area $\left(\mathrm{A}_{\mathrm{r}}\right)$ was calculated from the area of the hydrogen desorption region, which was then used to normalise the current to obtain current density [4]. A scan rate of $50 \mathrm{mVs}^{-1}$ was used for all the $\mathrm{CV}$ tests.

$m=\frac{Q M}{n F}$
Layer thickness $=\frac{Q M}{4 F \rho A}$

Commercial HisPEC-4000 Pt/C (40 wt\%) was used for $\mathrm{Pt} / \mathrm{C}$ catalyst ink preparation. The ink was prepared by mixing $5 \mathrm{mg}$ of the catalyst with $1.5 \mathrm{~cm}^{3}$ (ethanol + water) solvent and $20 \mu \mathrm{L}$ Nafion solution ( $5 \mathrm{wt} \%$ solution). The latter served both as adhesive and proton conductor. The mixture was then ultrasonicated for $30 \mathrm{~min}$ and $10 \mu \mathrm{L}$ ink was drop cast onto a GC electrode and dried at ambient temperature. The catalyst loading was ca. $68 \mu \mathrm{g} \mathrm{cm}^{-2}$ (Table 1). Cyclic voltammetry was conducted in the acid supporting electrolyte prior to the collection of data in the alcohol-containing solution.

XRD of the Pt/C sample was carried out using Panalytical $\mathrm{X}$-pert-Pro diffractometer with $\mathrm{Cu} \mathrm{K} \alpha$ radiation, step size $2 \theta=0.001^{\circ}$ and a $X^{\prime}$ Celerator RTMS detector. The crystallite size and lattice constant of the Pt particles were calculated using Eqs. (5) and (6) [53] where $d$ is the crystallite size, $\lambda$ is the $\mathrm{X}$-ray wavelength, $\beta$ is the full length at half maximum, $a$ is the lattice constant and $\theta$ is the XRD peak angle.

$d=\frac{0.9 \lambda}{\beta \cos \theta}$

$a_{f c c}=\frac{\sqrt{h^{2}+k^{2}+l^{2}} \lambda}{2 \sin \theta}$

\section{Results and Discussion}

\subsection{Methanol and Ethanol Oxidation Reaction on Electrodeposited Pt Film}

The CV of Pt in methanol and ethanol containing solution showed the characteristic oxidation peaks $a_{1}$ and $a_{2}$ during the anodic and cathodic scan respectively as given in Fig. 1 [25]. The effect of electrode rotation on the peak $a_{1}$ current density is also given in Fig. 1.

It is known that $\mathrm{CO}_{2}$ is formed together with significant quantities $\mathrm{HCHO}$ and $\mathrm{HCOOH}$ for the MOR on Pt [18, 20, $21,23,36,37]$. The EOR mechanism is also similar to MOR in that, it follows a dual path mechanism (Scheme 2b) [54]. However, it is much more complicated than MOR, due to the presence of the $\mathrm{C}-\mathrm{C}$ bond which requires higher energy to break. Ethanol mainly undergoes partial oxidation at lower potentials to form various soluble products such as $\mathrm{CH}_{3} \mathrm{CHO}$ and $\mathrm{CH}_{3} \mathrm{COOH}$ together with small amounts of $\mathrm{CO}_{2}[11,18$, $22,26,54-56]$. The soluble intermediate products formed can either be further oxidised to form $\mathrm{CO}_{2}$ at the catalyst surface or can dissolve in the electrolyte media (Scheme 2). 

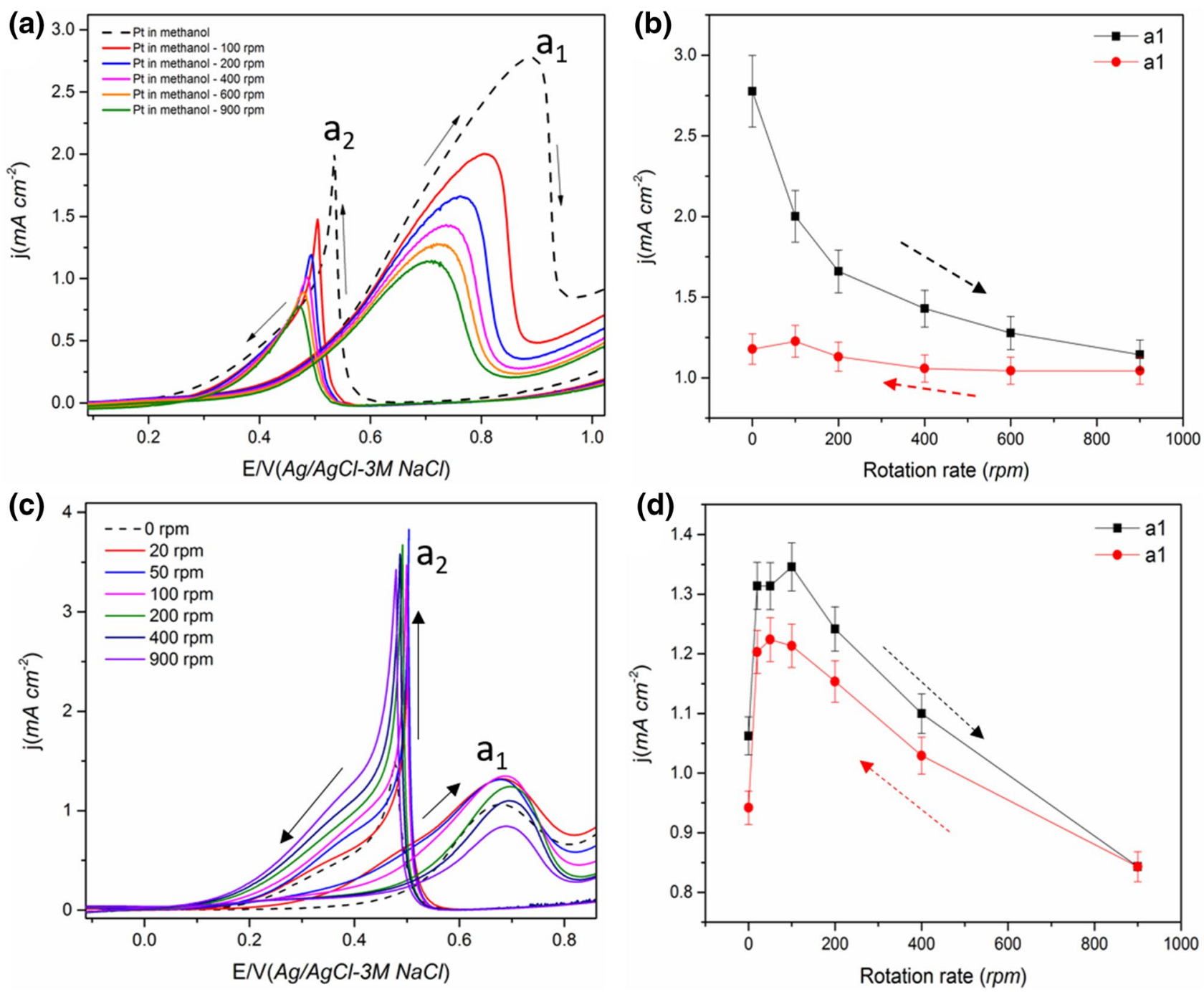

Fig. 1 The effect of electrode rotation rate $(\omega)$ on the cyclic voltammogram of electrodeposited Pt film electrode- 1 in (a, b) $0.5 \mathrm{M}$ methanol + $0.1 \mathrm{M} \mathrm{HClO}_{4}$ and peak $\mathrm{a}_{1}$ current density (c, d) electrode-2 in

The total current generated in the reaction can be expressed simply as Eq. (7), taking methanol as an example. The partial oxidation of the alcohol reduces the number of electrons generated per alcohol molecule and thus reduces the fuel efficiency [20, 23, 47].

$$
I_{\text {total }}=6 I_{\mathrm{CO}_{2}}+4 I_{\mathrm{HCOOH}}+2 I_{\mathrm{HCHO}}
$$

From Fig. 1, it is observed that the peak $a_{1}$ current decreases with an increase in $\omega$ for both methanol and ethanol. Since peak $a_{1}$ is associated with the corresponding alcohol oxidation, a decrease in current indicates a reduced reaction rate and/or reaction yield (number of electrons generated) with an increase in mass transport. A similar decrease in peak $a_{1}$ current for MOR with an increase in the $\omega$ was also reported previously for smooth Pt electrode [42] and $\mathrm{Pt}_{3}$ Co bulk alloy [41]. Considering a typical mass

$0.5 \mathrm{M}$ ethanol+0.1 $\mathrm{M} \mathrm{HClO}_{4}$ and peak $\mathrm{a}_{1}$ current density. Scan rate $50 \mathrm{mVs}^{-1}$. Solid arrow shows the direction of the potential scan

transport controlled reaction, the current is expected to increase with an increase in $\omega$. The decrease indicates that the reaction is not mass transport controlled and suggests increased diffusion of reactive species away from the electrode surface with an increase in $\omega[38,39,52]$. During the alcohol oxidation, a thin layer of increased concentration of $\mathrm{CO}_{2}$ and other intermediates compared to the bulk concentration will be formed close to the catalyst surface; on rotation, the alcohol from the bulk will have to diffuse through this thin layer where counter diffusion of $\mathrm{CO}_{2}$ and other soluble intermediates from the catalyst takes place [52]. i.e. the diffusion of intermediates from and convection of alcohol towards the catalyst are competing with the oxidation of the intermediates [20]. Hou et al. [52] observed a significantly lower diffusion coefficient of methanol $\left(\sim 10^{-12} \mathrm{~cm}^{2} \mathrm{~s}^{-1}\right)$ compared to the typical value $\left(\sim 10^{-5} \mathrm{~cm}^{2} \mathrm{~s}^{-1}\right)$ for smooth 

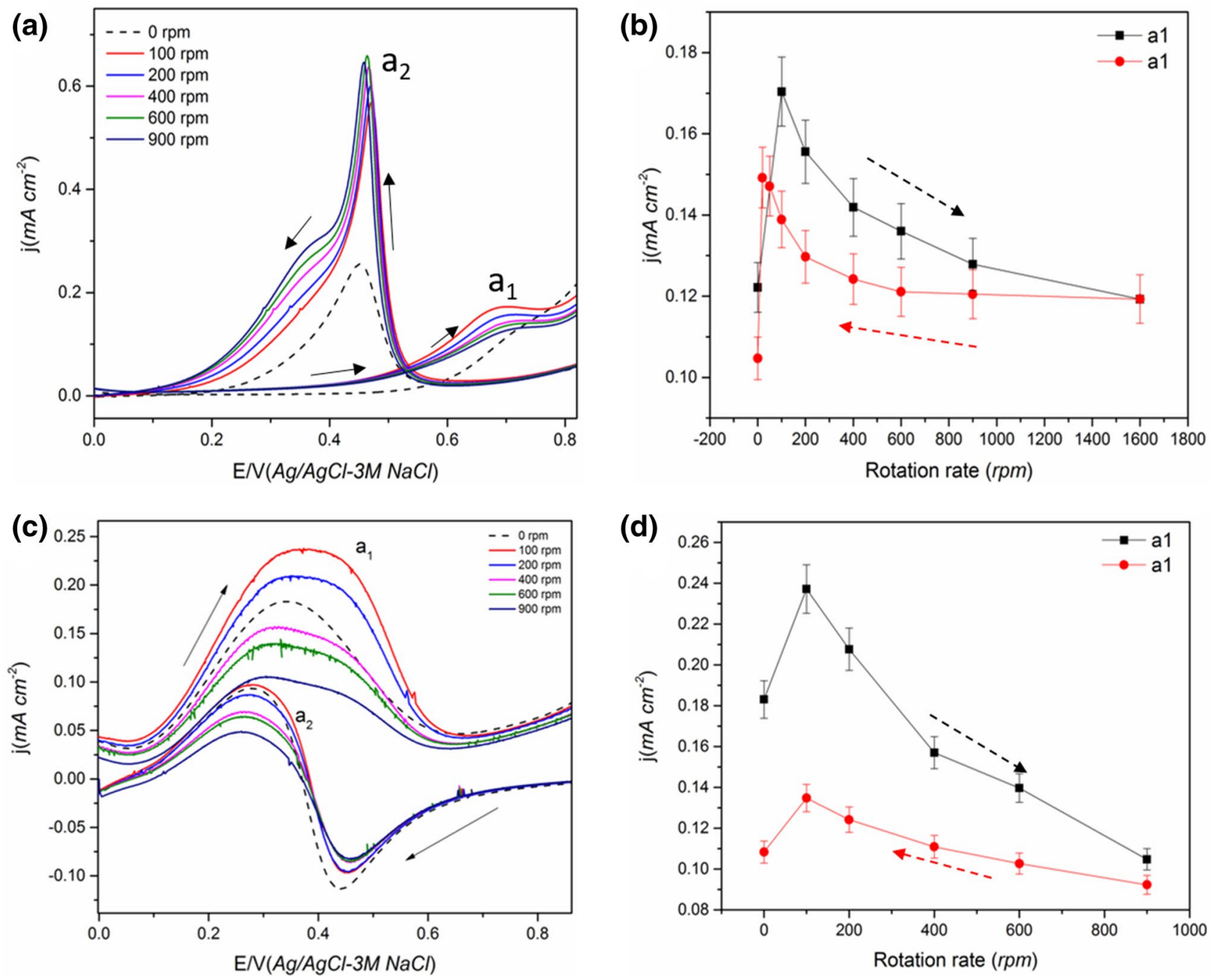

Fig. 2 The effect of electrode rotation on the CV of electrodeposited Pt film in (a, b) electrode- 2 in $0.5 \mathrm{M} n$-butanol+0.1 $\mathrm{M} \mathrm{HClO}_{4}$ solution and peak $\mathrm{a}_{1}$ current density. c, d Electrode- 3 in $0.1 \mathrm{M}$

2-butanol +0.1 $\mathrm{M} \mathrm{HClO}_{4}$ solution and peak $\mathrm{a}_{1}$ current density. Scan rate $50 \mathrm{mVs}^{-1}$ Arrow shows the direction of the potential scan. Scan rate $50 \mathrm{mVs}^{-1}$

Table 1 The Pt metal loading and layer thickness of the various electrodes used

\begin{tabular}{llll}
\hline Catalyst sample & Loading $\left(\mathrm{mg} \mathrm{cm}^{-2}\right)$ & $\begin{array}{l}\text { Catalyst layer thick- } \\
\text { ness }(\mu \mathrm{m})\end{array}$ & Notes \\
\hline $\begin{array}{l}\text { Electrode-1 } \\
\text { Electrode-2 }\end{array}$ & $0.48 \pm 0.10$ & $23 \pm 4$ & Figure 1a (methanol) \\
& $0.46 \pm 0.30$ & $21 \pm 3$ & $\begin{array}{l}\text { Figure 1c (etha- } \\
\text { nol) and Fig. 2a } \\
(n \text {-butanol) }\end{array}$ \\
Electrode-3 & $0.38 \pm 0.10$ & $18 \pm 3$ & Figure 2c (2-butanol) \\
Pt/C catalyst & $0.07(\mathrm{Pt})$ & - & Figures 4, 5 \\
Pt/C thicker catalyst layer & $0.14(\mathrm{Pt})$ & - & Figure 6 \\
\hline
\end{tabular}

Pt in chronoamperometry study, confirming the counter diffusion of soluble species from the catalyst. The convective removal of the partial oxidation products on rotation makes them unavailable for further oxidation reducing the total number of electrons released per molecule in the reaction as given in Eq. (7) for MOR. i.e. $\mathrm{CO}_{2}$ is formed only by the $\mathrm{CO}_{\text {ads }}$ pathway at higher $\omega$ for MOR whereas, in static solution, both pathways contribute towards the current. 
Scheme 2 Schematic of electrochemical oxidation on $\mathrm{Pt}$ in acidic media of (a) methanol (b) ethanol

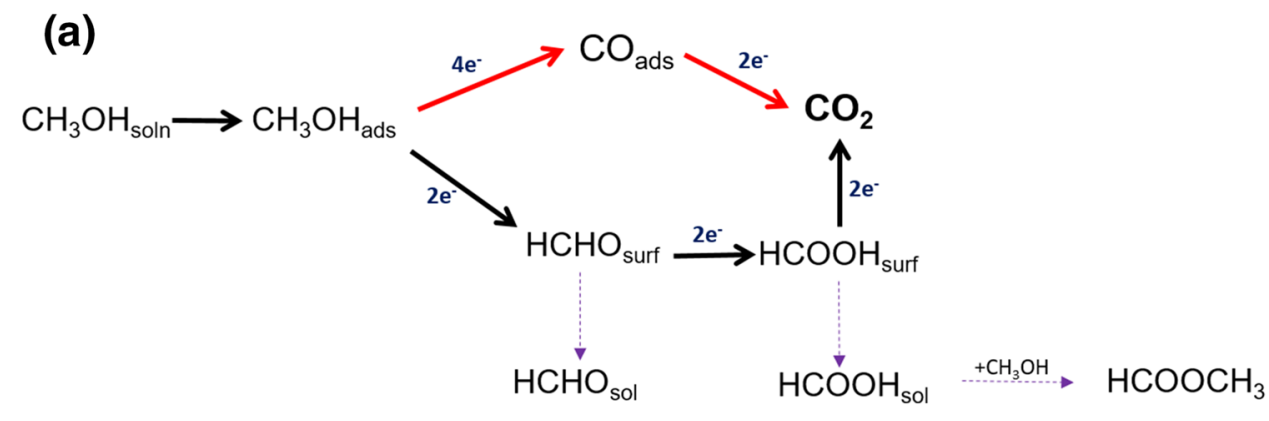

(b)

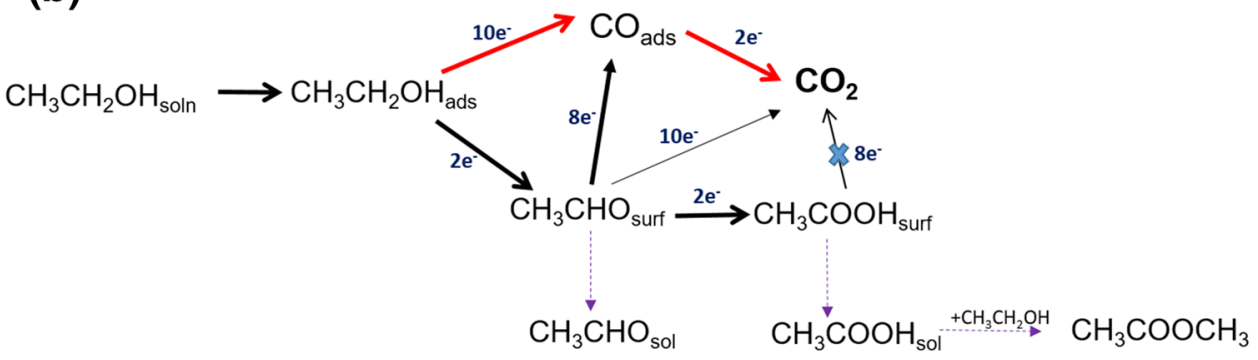

However, the removal of partial oxidation products and the increased consumption of alcohol should increase the formation of the soluble products (eg: $\mathrm{CH}_{3} \mathrm{OH} \rightarrow \mathrm{HCHO}$ for MOR) and increase the current through this pathway. Seland et al. [38] proposed that the increase in current through this pathway is surpassed by a decrease in current through the $\mathrm{CO}_{\text {ads }}$ pathway due to an increased $\mathrm{CO}_{\text {ads }}$ coverage at higher $\omega$. They confirmed this by observing an increase in peak current following a transient increase in $\omega$ for MOR (when rotation suddenly changed from low to very high) [38, 39]. This increase was attributed to the fact that, a transient increase in $\omega$ does not affect the $\mathrm{CO}_{\text {ads }}$ pathway and does not change the Pt surface state but enhances the HCHO pathway and subsequently increases the total current [38, 39]. A gradual increase in $\omega$, on the other hand, increases the adsorption of alcohol over water favouring the formation of $\mathrm{CO}_{\text {ads }}$ over the $\mathrm{OH}_{\mathrm{ads}}$, which in turn increases the $\mathrm{CO}_{\text {ads }}$ coverage on the $\mathrm{Pt}$ surface, blocking the active sites leading to a reduced current $[39,42]$. A decrease in $\mathrm{CO}_{2}$ current efficiency during MOR with an increase in flow rate has been observed in previous DEMS studies [20, 36, 48], confirming incomplete oxidation of methanol to $\mathrm{CO}_{2}$. This reasoning can also be applied to EOR (Fig. 1c and Scheme 2b).

On stopping the rotation at $900 \mathrm{rpm}$ following the increase in $\omega$, both the peak current for $\mathrm{a}_{1}$ and $\mathrm{a}_{2}$ increase slightly and on applying the rotation again, the current decreases for both methanol and ethanol (not shown). This confirms the role of the diffusion of soluble intermediates and rules out the possibility of a contaminant in the electrolyte being responsible for the decrease in peak current (increased diffusion of contaminants to the electrode) [42]. In addition, on reducing the $\omega$, the peak $\mathrm{a}_{1}$ current increases for methanol and ethanol with the change found to be reversible in the case of ethanol (Fig. 1d) compared with methanol (Fig. 1b). This indicates that the surface state might have changed significantly during the increase in $\omega$ for MOR making it less active. As mentioned above, this could be due to the high coverage of $\mathrm{CO}_{\text {ads }}$ on the Pt surface with an increase in rotation leading to a more irreversible blocking effect. Even though a higher potential is expected to oxidise $\mathrm{CO}_{\text {ads }}$ completely, this will only happen if there are sufficient $\mathrm{OH}_{\text {ads }}$ present on the catalyst surface. The $\mathrm{OH}_{\text {ads }}$ coverage is likely to be reduced at higher rotation rates due to increased coverage by methanol. This indicates that the $\mathrm{CO}_{\text {ads }}$ or other strongly adsorbed intermediate coverage is higher at higher $\omega$ for MOR [42] decreasing the number of $\mathrm{Pt}$ active sites available for methanol oxidation during the subsequent decrease in $\omega$.

The reversibility of the peak $\mathrm{a}_{1}$ current on decreasing the $\omega$ for EOR indicates that $\mathrm{CO}_{\text {ads }}$ cannot be the cause of the decrease in current. Unlike MOR, the EOR mainly leads to $\mathrm{C}_{2}$ intermediates [22], and the formation of strongly adsorbed intermediates such as $\mathrm{CO}_{\text {ads }}$ is lower than that for MOR due to the poor reaction kinetics of ethanol/lower activity for $\mathrm{C}-\mathrm{C}$ bond cleavage. Therefore, in this case, the surface state of $\mathrm{Pt}$ is unlikely to have changed significantly with an increase in $\omega$, as the intermediate soluble species are removed at higher $\omega$. On decreasing the $\omega$, the Pt active sites will then be available for adsorption and oxidation of the ethanol. Since $\mathrm{CH}_{3} \mathrm{COOH}$ is difficult to further oxidise at the potential range of peak $\mathrm{a}_{1}$ [32], the diffusing species is possibly $\mathrm{CH}_{3} \mathrm{CHO}$. Also, the production of aldehyde is not significantly influenced by water whereas the production of acidic species requires water on the catalyst surface [11]. 
Thus, the influence of rotation on water oxidation reaction will also influence the alcohol oxidation product distribution. As the water adsorption is less dominant at higher $\omega$, the major product and diffusing species at peak $\mathrm{a}_{1}$ are likely to be $\mathrm{CH}_{3} \mathrm{CHO}$ in the case of EOR.

The trends found for the current of peak $\mathrm{a}_{2}$ were the same as that of peak $a_{1}$ for methanol, i.e. decrease with increase in $\omega$ (Fig. S2) [38, 42]. For methanol, the peak $a_{2}$ is generally attributed to the re-oxidation of intermediates formed (eg: $\mathrm{CH}_{\mathrm{x}} \mathrm{O}$ ) during the anodic scan as well as fresh methanol adsorption on the oxide-free Pt surface [25, 49]. However, using in-situ surface enhanced IR absorption spectroscopy (SEIRAS), Duffy et al. [57] observed that the $\mathrm{a}_{2}$ peak solely comes from freshly adsorbed methanol and not from the remaining carbonaceous species from the anodic scan. The decrease in peak current could be explained as in the case of peak $\mathrm{a}_{1}$; i.e. diffusion of soluble intermediate species at higher $\omega$ for MOR. For EOR, unlike the trend found for MOR, the current for peak $a_{2}$ showed an initial increase on increasing $\omega$ to $100 \mathrm{rpm}$ and thereafter it remained constant with further increases in $\omega$ (Fig. S2b). The peak $a_{2}$ for EOR associated with the oxidation of freshly adsorbed ethanol on the reduced oxide-free sites mainly forming $\mathrm{CH}_{3} \mathrm{CHO}$ and $\mathrm{CH}_{3} \mathrm{COOH}[18,22,39,40]$. No $\mathrm{CO}_{2}$ formation was reported for the peak $a_{2}$ for EOR. An increase in current for peak $a_{2}$ on rotation was also observed by Seland et al. [39]. This was thought to be due to a slow formation of adsorbed species at the potential of the peak $a_{2}$ for ethanol compared to the fast formation of $\mathrm{CO}_{\mathrm{ads}}$ for methanol. On decreasing the $\omega$, the peak current behaved similarly to that during the increase in $\omega$ (Fig. S2b). The lack of any changes in the peak current is consistent with the fact that the reaction is not mass transport controlled.

\subsection{Butanol Oxidation on Electrodeposited Pt Film}

As found with methanol and ethanol, the current density for peak $\mathrm{a}_{1}$ decreased with an increase in $\omega$ for both $n$-butanol and 2-butanol as shown in Fig. 2. The near reversibility of peak $a_{1}$ current on decreasing $\omega$ was also observed for $n$-butanol as in the case of ethanol; whereas the 2-butanol behaved similarly to methanol with poor reversibility (Fig. 2d). The same reasoning for ethanol can be applied for $n$-butanol, although it should be noted that the $\mathrm{CO}_{\text {ads }}$ coverage will be even lower in the case of $n$-butanol than during EOR. Mukherjee and Bhattacharya [58] observed the formation of aldehyde and ester groups during $n$-butanol oxidation on Pt and Pd electrodes in alkaline media using in-situ FTIR and this was attributed to butyraldehyde and butyric acid formation. Nan-Hai and Shi-Gang [33] also conducted an in-situ FTIR study of $n$-butanol on Pt in acidic media and concluded that the formation of butyric acid (or via butyraldehyde) is the major reaction pathway, indicating that the
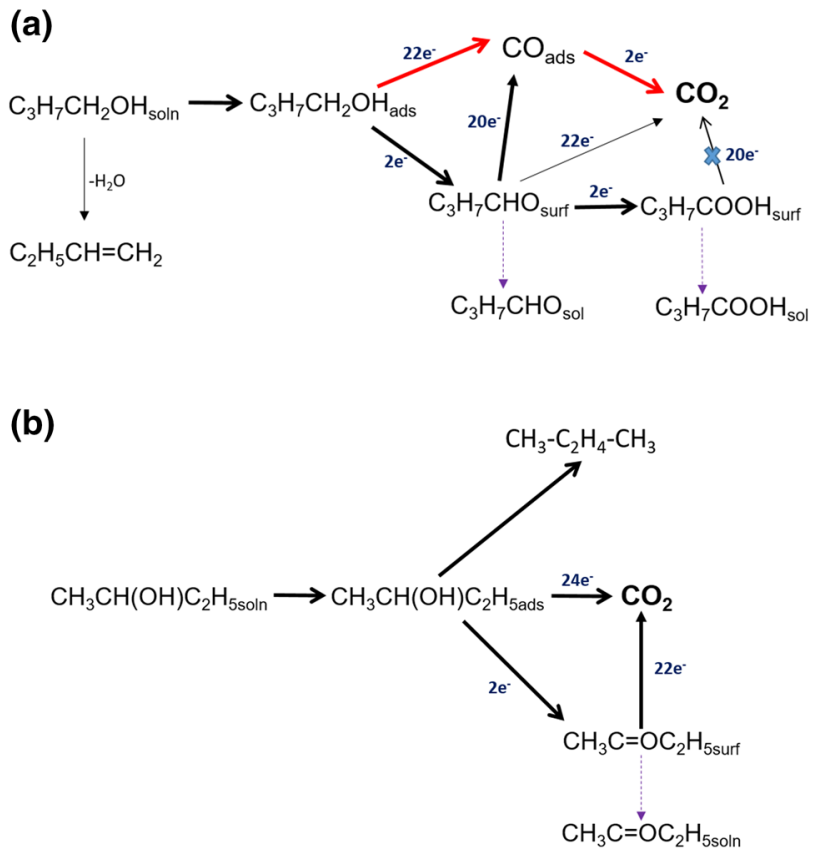

Scheme 3 The schematic of electro-oxidation on Pt in acidic media of (a) $n$-butanol (b) 2-butanol

complete oxidation to $\mathrm{CO}_{2}$ is low (Scheme 3). Gootzen et al. [59] observed the formation of $\mathrm{CO}_{2}$ in the peak $\mathrm{a}_{1}$ region using DEMS on Pt in $n$-butanol containing acidic solution. The decrease with the increase in $\omega$ for the 2-butanol confirms that the $\mathrm{CO}_{\text {ads }}$ coverage cannot be the reason for a decrease in peak current as the formation of ketonic species is the dominant reaction at peak $\mathrm{a}_{1}$ for 2-butanol [60], which can easily diffuse away from the catalyst surface on rotation. In addition, peak $\mathrm{a}_{1}$ for 2-butanol is not affected by water oxidation as the potential of peak $a_{1}$ is significantly lower compared to other primary alcohol molecules. Since diffusion of ketonic species reduces the further oxidation of ketone, the total current decreases. As no $\mathrm{CO}_{\mathrm{ads}}$ but $\mathrm{CO}_{2}$ was observed during 2-butanol oxidation [4], the $\mathrm{CO}_{2}$ might have formed from butanone at high potential (Scheme $3 b$ ).

An initial increase in the current density was observed, up to $100 \mathrm{rpm}$, followed by a decrease with increasing $\omega$ for butanol oxidation (Fig. 2), similar to that observed for the ethanol oxidation reaction (Fig. 1). It could be presumed that the diffusion of soluble species from the electrode is not dominant at low $\omega$ compared with the transport of alcohol to the electrode under the experimental conditions employed. To further investigate whether the initial increase up to $100 \mathrm{rpm}$ is due to the insignificant diffusion of intermediates, the rotation was increased directly to 900 from $0 \mathrm{rpm}$ during 2-butanol oxidation (Fig. S3). A decrease in current was observed in this case indicating that at higher rotation the intermediates diffuse away whereas at $100 \mathrm{rpm}$ this is not the case. 
Peak $a_{2}$ for $n$-butanol also showed a similar trend to that of ethanol, i.e. an initial increase and then a stable peak current with further increases in $\omega$ (Fig. S2). The peak $a_{2}$ also showed a decrease in the peak current for 2-butanol (Fig. S2d) as in the case of methanol.

\subsection{Alcohol Oxidation Reactions on Carbon-Supported Pt Catalyst (Pt/C)}

The XRD of $\mathrm{Pt} / \mathrm{C}(40 \%)$ commercial catalyst is given in Fig. 3. A characteristic feature of face centred cubic (fcc) structure of $\mathrm{Pt}$ was obtained. The crystallite size $(d)$ and lattice constant $\left(a_{f c c}\right)$ from Pt (220) plane was ca. $3.3 \mathrm{~nm}$ and 391.4 pm respectively.

\subsubsection{Methanol and 2-Butanol Oxidation on $\mathrm{Pt} / \mathrm{C}$}

The effect of $\omega$ on carbon supported Pt nanoparticle (Pt/C) in methanol and 2-butanol containing solution is given in Fig. 4. Similar to the electrodeposited Pt film, a decrease in current with an increase in $\omega$ was observed for both alcohols. This indicates that the diffusion of soluble species could also be dominant on Pt/C. However, an increase in peak current with rotation for $\mathrm{Pt} / \mathrm{C}$ has been reported for MOR when a higher catalyst loading of Pt/C was used [47]. Sayadi and Pickup [47] used a loading of $10 \mathrm{mg} \mathrm{cm}^{-2}$ of $20 \% \mathrm{Pt} / \mathrm{C}$ and observed an increase in methanol oxidation peak current on rotation of the electrode. The discrepancy with the current result could be due to the relatively lower catalyst loading used in the current study. When a thicker catalyst layer $\left(0.14 \mathrm{mg} \mathrm{Pt} \mathrm{cm}^{-2}\right)$ was used, the peak current density did not decrease with rotation (Fig. 6). This confirms that at higher catalyst layer thickness (loading), the removal of the $\mathrm{HCHO}$ is restricted and the reaction becomes

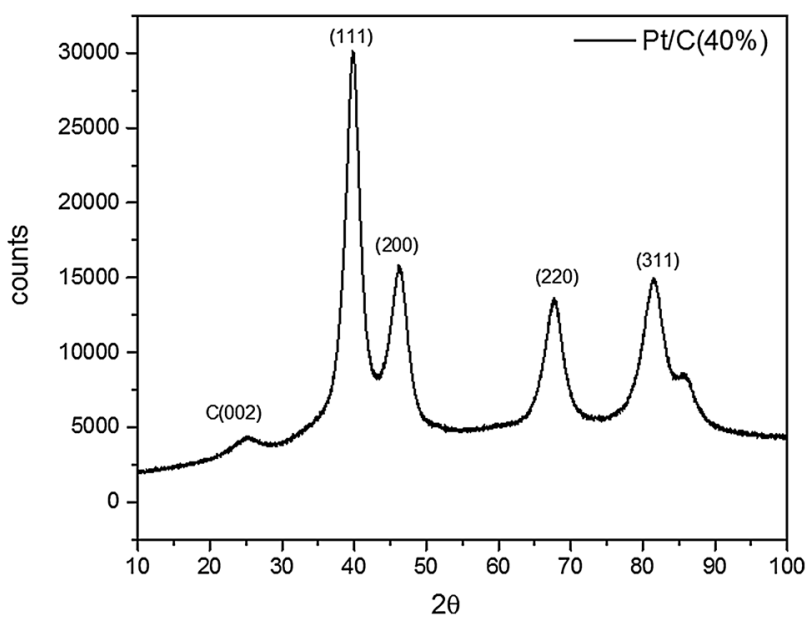

Fig. 3 XRD spectra of the commercial Pt/C (40\%) catalyst. The XRD peak shows the fcc structure of Pt particles independent of the rotation rate. Gojkovic [42] also observed non-dependence of peak current with rotation for MOR on $\mathrm{Pt} / \mathrm{C}$ catalyst. Sayadi and Pickup [51] observed a non-linear Koutecky-Levich (K-L) plot for EOR on Pt/C when thin catalyst layer was used indicating a lack of pure diffusion controlled reaction on the thin catalyst layer. At an even higher catalyst layer thickness, an increase in peak current with rotation rate could be expected as a complete oxidation of methanol to $\mathrm{CO}_{2}$ can occur leading to mass transport controlled reaction. In other words, it could be inferred that there is a threshold catalyst layer thickness for methanol oxidation (at a certain concentration and temperature) above which reaction become mass transport controlled and below which the reaction decreases. This threshold thickness value is different for different alcohol molecules as they have different reaction rates, reaction mechanisms and intermediate species formed. For example, in the case of ethanol at the same thickness as methanol $\left(0.14\right.$ and $\left.0.07 \mathrm{mg} \mathrm{cm}^{-2}\right)$ the peak current decrease (Fig. 6). So the threshold catalyst loading for ethanol oxidation reaction is lower than that for methanol.

An increased $\mathrm{CO}_{2}$ efficiency on $\mathrm{Pt} / \mathrm{C}$ (ca. $88 \%$ on

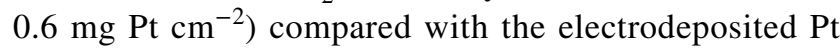
film (ca. 30\%) has been reported in DEMS studies for MOR [21] indicating complete oxidation on carbon supported $\mathrm{Pt}$ catalysts. Childers et al. [37] observed that over carbon supported $\mathrm{Pt}$ and $\mathrm{PtRu}$, methanol tends to undergo complete oxidation at lower potential as the retention time of the partial oxidation product $\mathrm{HCHO}$ is higher in these cases which help its further oxidation to $\mathrm{CO}_{2}$. Electrodeposited Pt film showed higher HCHO formation compared to $\mathrm{Pt} / \mathrm{C}$. It is clear from Fig. 4 that the peak currents at all $\omega$ 's are higher than those in the quiescent solution, which, is in agreement with the higher retention time of intermediates on the catalyst surface and the improved overall oxidation efficiency as well as improved transport of alcohol to the catalyst surface.

\subsubsection{Ethanol and $n$-Butanol Oxidation on $\mathrm{Pt} / \mathrm{C}$}

In contrast, in the case of ethanol (Fig. 5a) and $n$-butanol (Fig. 5c), an increase in peak current was observed with increase in $\omega$. A similar trend was also reported previously for ethanol oxidation on $\mathrm{Pt} / \mathrm{C}$ for both peaks $\mathrm{a}_{1}$ and $\mathrm{a}_{2}[50$, 51]. This was attributed to the enhancement of the fast ethanol supply to the active sites free of ethanol adsorbates which formerly oxidised into acetaldehyde (kinetics of this reaction is fast). A higher residence time of intermediate species on the carbon supported catalyst layer and subsequent hindrance of the diffusion of soluble species away from the corrugated $\mathrm{Pt} / \mathrm{C}$ surface leading to a more complete oxidation $[21,42,50]$. Also, the intermediates formed on $\mathrm{Pt} / \mathrm{C}$ may remain in the proximity of the catalyst surface increasing the chance of re-adsorption and further oxidation 

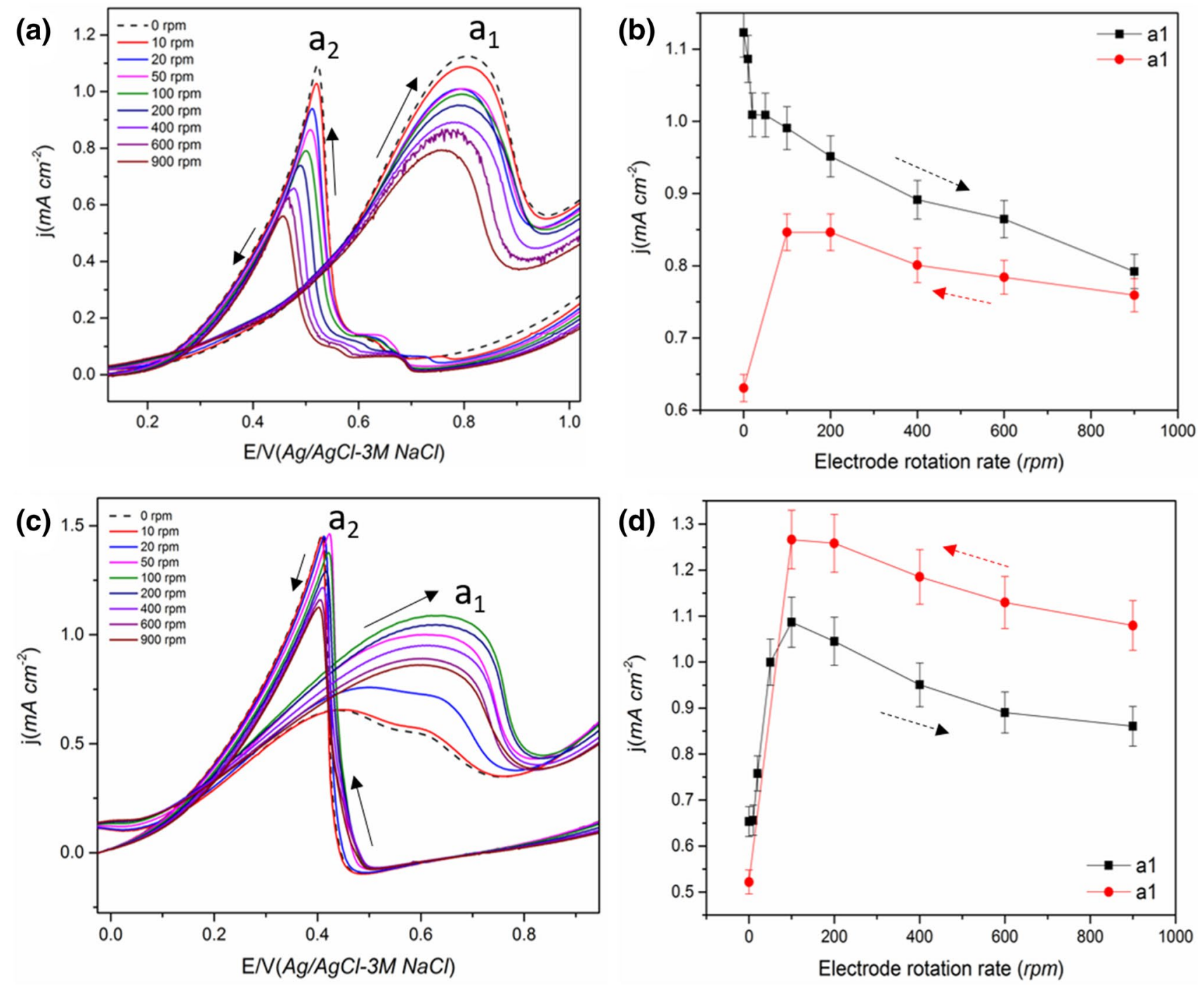

Fig. 4 a, b The effect of electrode rotation on $\mathrm{Pt} / \mathrm{C}$ (40 wt \%) catalyst in $0.5 \mathrm{M}$ methanol+0.1 $\mathrm{M} \mathrm{HClO}_{4}$ solution and evolution of peak $\mathrm{a}_{1}$ current. c, $\mathbf{d}$ The effect of electrode rotation on the peak current of

to $\mathrm{CO}_{2}$ (Scheme 4). It has to be noted the Pt metal loading for the $\mathrm{Pt} / \mathrm{C}\left(0.07 \mathrm{mg} \mathrm{cm}^{-2}\right)$ was ca. six times lower than that for the electrodeposited film $\left(0.46 \mathrm{mg} \mathrm{cm}^{-2}\right)$ and still an increase in current was observed indicating that rough carbon surface has a significant influence on the diffusion of reactive species. Katayanagi and Yamazaki [46] studied the effect of flow rate on the ethanol oxidation reaction on the anode of a single cell and observed that with an increase in flow rate, the $\mathrm{CO}_{2}$ production decreases. In addition, the $\mathrm{CO}_{2}$ production increases when acetaldehyde production decreases on the catalyst surface, i.e. with an increase in flow rate, more acetaldehyde is produced. Sayadi and Pickup [51] proposed that the increase in current could also be due to the fact that $\mathrm{CH}_{3} \mathrm{CHO}$ acts as a poison for the catalyst and on a thick catalyst layer the oxidation of $\mathrm{CH}_{3} \mathrm{CHO}$ to $\mathrm{CH}_{3} \mathrm{COOH}$
$\mathrm{Pt} / \mathrm{C}(40 \%)$ catalyst in $0.5 \mathrm{M}$ 2-butanol+0.1 $\mathrm{M} \mathrm{HClO}_{4}$ solution. Scan rate $50 \mathrm{mVs}^{-1}$ Solid arrow shows the direction of the potential scan

becomes easier. The removal of $\mathrm{CH}_{3} \mathrm{CHO}$ thus increases the current due to the improved adsorption of alcohol. Peak $\mathrm{a}_{2}$ was found to vary more with rotation compared to peak $a_{1}$ for all the alcohols tested on Pt/C. A similar observation was also made by Sayadi and Pickup [51] on Pt/C during EOR.

The average number of electrons $\left(n_{a v}\right)$ transferred in the EOR on $\mathrm{Pt} / \mathrm{C}$ is calculated using Koutecky-Levich plot $\left(i^{-1}\right.$ vs. $\left.\omega^{-1 / 2}\right)$ (Fig. S5) as per Eq. (8) $[47,51,52]$ where $i_{k}$ is the kinetic current, $i_{L}$ is the limiting current (Levich current), $n_{a v}$ is the number of electrons transferred in the reaction, $A$ is the area of the electrode, $F$ is the Faraday constant $\left(96,485 \mathrm{C} \mathrm{mol}^{-1}\right), D$ is the diffusion coefficient of the alcohol molecule $\left(1.22 \times 10^{-5} \mathrm{~cm}^{2} \mathrm{~s}^{-1}\right.$ for aqueous ethanol at $25{ }^{\circ} \mathrm{C}$ ) [51], $v$ is the kinematic 

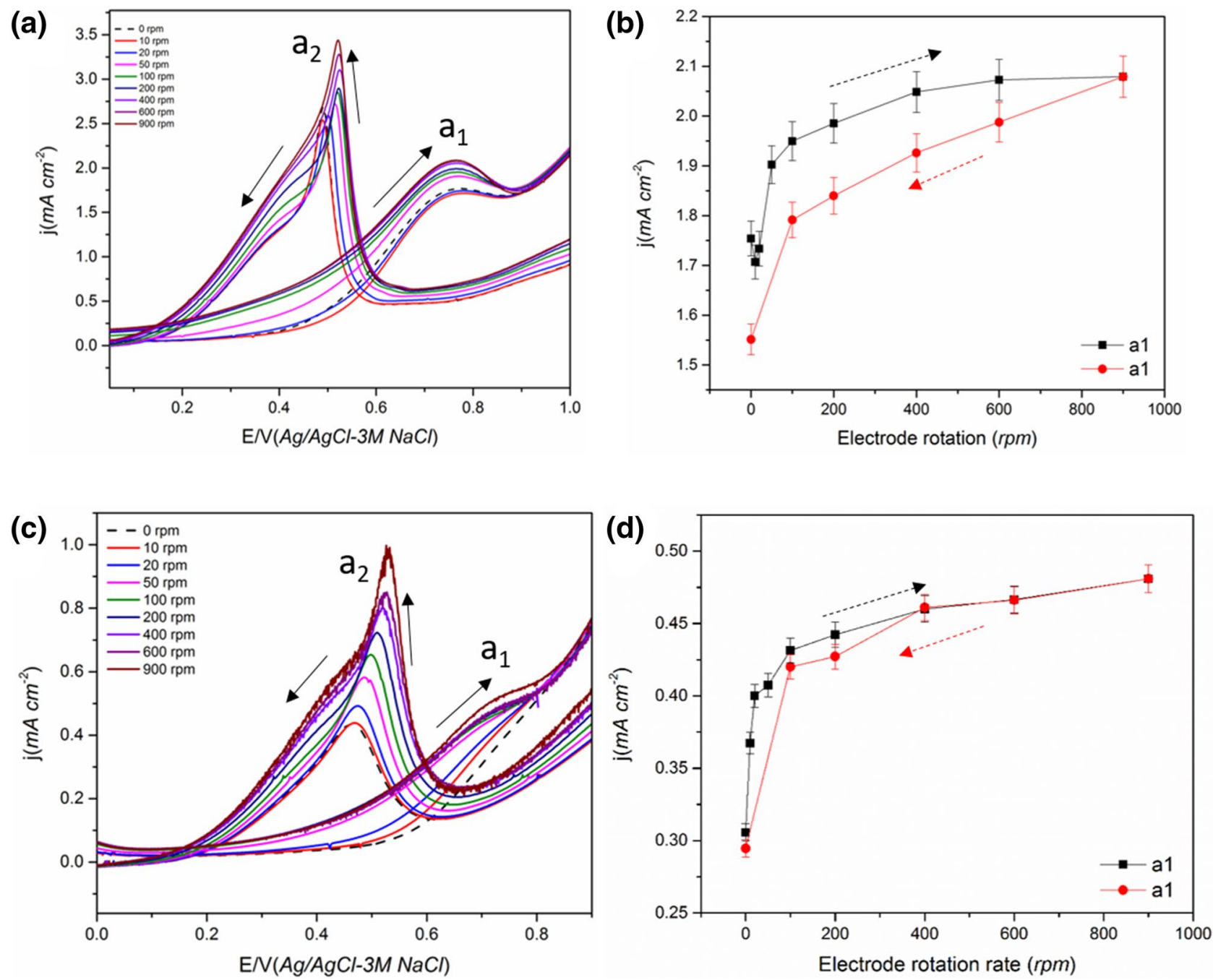

Fig. 5 a, b The effect of electrode rotation in $0.5 \mathrm{M}$ ethanol $+0.1 \mathrm{M}$ $\mathrm{HClO}_{4}$ solution on $\mathrm{Pt} / \mathrm{C}(40 \mathrm{wt} \%$ ) catalyst and the evolution of peak $a_{1}$ current during the increase and decrease in the $\omega$. c, $\mathbf{d}$ The effect

of electrode rotation in $0.5 \mathrm{M} \mathrm{n}$-butanol $+0.1 \mathrm{M} \mathrm{HClO}_{4}$ on $\mathrm{Pt} / \mathrm{C}$ (40 wt $\%$ ) catalyst and the evolution of peak $\mathrm{a}_{1}$ current on increase and decrease in $\omega$

viscosity $\left(1.0 \times 10^{-2} \mathrm{~cm}^{2} \mathrm{~s}^{-1}\right)[47,51], C$ is the concentration $\left(\mathrm{mol} \mathrm{cm}^{-3}\right)$ and $\omega$ is the rotation rate (radians per second).

$\frac{1}{i}=\frac{1}{i_{k}}+\frac{1}{i_{L}}=\frac{1}{i_{k}}+\frac{1}{0.62 n_{a v} F A D^{2 / 3} v^{-1 / 6} C \omega^{1 / 2}}$

Using a literature value of ethanol diffusion coefficient in water at $25{ }^{\circ} \mathrm{C}, 1.22 \times 10^{-5} \mathrm{~cm}^{2} \mathrm{~s}^{-1}[51]$, the average number of electrons $(n)$ at $0.75 \mathrm{~V}$ was calculated to be 0.2 , which is not a realistic value whereas when lower $D$ value was used $\left(1.22 \times 10^{-7} \mathrm{~cm}^{2} \mathrm{~s}^{-1}\right)$, the $n$ value was found to be $\sim 4.2$ which is more realistic value for a partial oxidation of ethanol to acetic acid. This discrepancy in the value of

Scheme 4 The schematic of the effect of rotation rate $(\omega)$ on carbon supported and electrodeposited Pt film electrode 

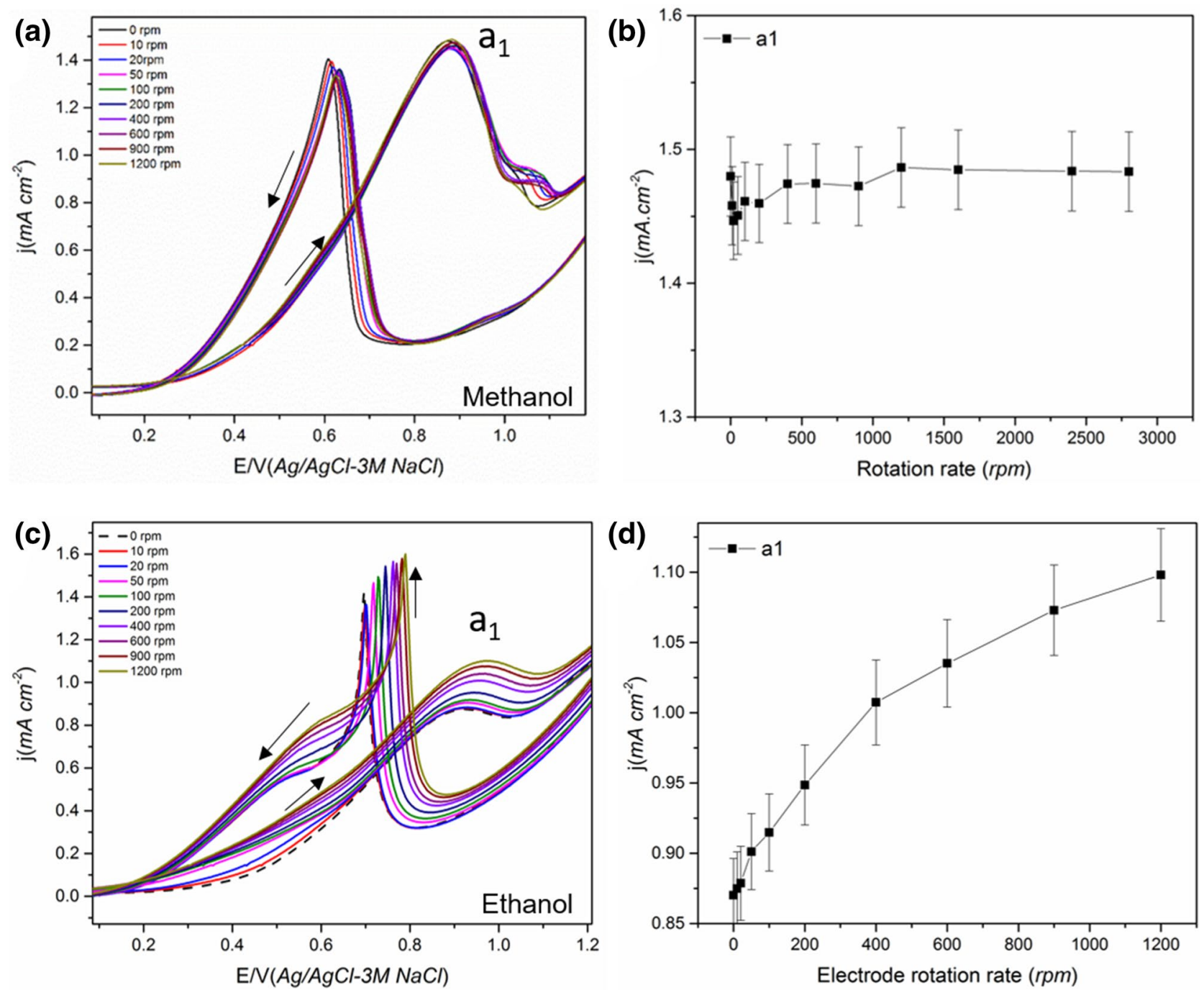

Fig. 6 The effect of electrode rotation rate on the $\mathrm{CV}$ and peak a1 current of (a, b) $0.5 \mathrm{M}$ methanol+0.1 $\mathrm{M} \mathrm{HClO}_{4}$ and (c, d) $0.5 \mathrm{M}$ etha$\mathrm{nol}+0.1 \mathrm{M} \mathrm{HClO}_{4}$ solution on a thicker Pt/C catalyst layer $\left(0.14 \mathrm{mg} \mathrm{cm}^{-2}\right)$

occurs during the rotation of the electrode making the net diffusion coefficient lower (Table 2). Moreover, the limiting current $\left(i_{L}\right)$ calculated using Eq. (8) for ethanol oxidation on $\mathrm{Pt} / \mathrm{C}$ at $900 \mathrm{rpm}$ was ca. $0.78 \mathrm{~A}$ using the parameters described in Table 3 which is large compared to what was obtained from the experiment and can only be due to the error in the diffusion coefficient value [52]. Such discrepancies in D value were also reported previously for MOR [52].

The similarity between methanol and 2-butanol and that between ethanol and $n$-butanol, on both electrodeposited Pt film and $\mathrm{Pt} / \mathrm{C}$ is noticeable. Methanol and 2-butanol are the most reactive alcohols whereas ethanol and $n$-butanol have relatively sluggish reaction kinetics. Less reactive molecules such as ethanol and $n$-butanol will not change the Pt active surface as significantly compared to more reactive molecules such as methanol and 2-butanol due to lower reaction intermediate products formed. A large number of intermediates (e.g. $\mathrm{HCHO}, \mathrm{CO}_{\mathrm{ads}}$ ) could be formed during MOR and a lower Pt/C loading might not be sufficient to hinder its diffusion away from the electrode. Peak $\mathrm{a}_{2}$ also showed a similar trend with increasing rotation as peak $\mathrm{a}_{1}$ for both ethanol and $n$-butanol (Fig. S4). This was confirmed by doubling the Pt/C catalyst loading (Fig. 6). In this case, the methanol oxidation peak current was independent of the rotation rate whereas, for ethanol, the peak current was found to be increasing with an increase in rotation rate as found for the lower catalyst loading case. As mentioned in Sect. 3.3.1, this could be due to the increased resident time of the MOR reaction intermediates in the catalyst. The threshold catalyst loading above which the reaction becomes mass transport limited is lower for ethanol than methanol due to the sluggish kinetics of EOR. 
Table 2 The $\mathrm{n}_{\mathrm{av}}$ and diffusion coefficient values from K-L plot for ethanol oxidation on $\mathrm{Pt} / \mathrm{C}$

\begin{tabular}{lllll}
\hline Potential & $\begin{array}{l}\mathrm{n}_{\mathrm{av}} \text { for } \\
\mathrm{D}=1.22 \times 10^{-5} \mathrm{~cm}^{2} \mathrm{~s}^{-1}\end{array}$ & $\begin{array}{l}\mathrm{n}_{\mathrm{av}} \text { for } \\
\mathrm{D}=1.22 \times 10^{-7} \mathrm{~cm}^{2} \mathrm{~s}^{-1}\end{array}$ & $\begin{array}{l}\text { D calculated } \\
\text { from theoreti- } \\
\mathrm{cal} \mathrm{n}_{\text {av }} \text { value }=4 \\
\left(\mathrm{~cm}^{2} \mathrm{~s}^{-1}\right)\end{array}$ & $\begin{array}{l}\text { D calcu- } \\
\text { lated from } \\
\text { theo- } \\
\text { retical } \mathrm{n}_{\mathrm{av}} \\
\text { value }=12 \\
\left(\mathrm{~cm}^{2} \mathrm{~s}^{-1}\right)\end{array}$ \\
\hline $0.75 \mathrm{~V}$ & 0.20 & 4.20 & $1.31 \times 10^{-7}$ & $2.52 \times 10^{-8}$ \\
\hline
\end{tabular}

Data from Fig. 5a

From the above results, it can be concluded that the increase in current on carbon supported catalyst is likely to be a combination of (i) a change in the reaction mechanism from a $\mathrm{CO}_{\mathrm{ads}}$ dominant pathway on electrodeposited $\mathrm{Pt}$ film to being partial oxidation dominated on $\mathrm{Pt} / \mathrm{C}$, and/or, (ii) relatively poor removal of the intermediates and higher chances of re-adsorption of intermediates in presence of a carbon supported Pt surface. Hayes et al. [29] observed a decrease in peak current with an increase in the $\omega$ for Pt disk electrode in alkaline media whereas, for nanoporous $\mathrm{Pt}$, the current was found to increase with an increase in $\omega$. This was attributed to the trapping of non-adsorbed intermediate species inside the pores which otherwise would sweep away on rotation increasing the chance of its further oxidation. Zhang et al. [61] also observed a higher activity of a porous $\mathrm{Au}$ electrode for MOR and attributed this to the trapping of $\mathrm{OH}^{-}$ion in the pores. These, along with the results obtained, herein, indicate the importance of increasing the residence time of the intermediates on the catalyst surface in designing new more efficient catalysts.

\section{Conclusions}

The mass transport effects on the electro-oxidation of various alcohol molecules (methanol, ethanol, $n$-butanol and 2-butanol) on both electrodeposited Pt and carbon supported $\mathrm{Pt}(\mathrm{Pt} / \mathrm{C})$ catalysts were studied systematically to understand the catalyst activity under non-steady state conditions. A

Table 3 Limiting current $\left(i_{L}\right)$ calculation of Pt/C catalyst for ethanol oxidation reaction

\begin{tabular}{ll}
\hline Variable & Value \\
\hline Faradays constant $(F)$ & $96,485 \mathrm{C} \mathrm{mol}^{-1}$ \\
Geometrical area $(A)$ & $0.196 \mathrm{~cm}^{2}$ \\
Diffusion coefficient $(D)$ & $1.22 \times 10^{-5} \mathrm{~cm}^{2} \mathrm{~s}^{-1}$ \\
Kinematic viscosity $(\nu)$ & $0.01 \mathrm{~cm}^{2} \mathrm{~s}^{-1}$ \\
Ethanol concentration $(C)$ & $0.5 \mathrm{~mol} \mathrm{~cm}^{-3}$ \\
Electrons transferred $(n)$ & 12 \\
$\omega$ at 900 rpm & $94.2 \mathrm{rad} \mathrm{s}^{-1}$ \\
Limiting current $\left(i_{L}\right)$ & $0.78 \mathrm{~A}$ \\
\hline
\end{tabular}

clear dependence of the effect of mass transport on the thickness of the catalyst layer and the type of the alcohol molecules were observed where the electrodeposited film was used as the model system for the thinnest catalyst layer and carbon supported Pt was used as a model to thicker and corrugated catalyst surface. It was found that increasing mass transport has a negative effect on the oxidation of the alcohol molecules on thinner catalyst layer (electrodeposited Pt film). The decrease in peak current is attributed to a combination of factors; (i) removal of the partial oxidation products from the catalyst surface making it unavailable for further oxidation and/or (ii) a shift in the dominant reaction mechanism pathway to the one forming more strongly adsorbed intermediates under rotation condition, blocking the Pt active sites.

On the other hand, on the $\mathrm{Pt} / \mathrm{C}$ catalyst surface two different trends were observed. On a thinner $\mathrm{Pt} / \mathrm{C}$ catalyst layer (i.e. lower loading), the methanol and 2-butanol oxidation current decrease with increase in rotation. However, on a higher thickness of the catalyst layer, the decrease was prevented and a steady state current was maintained for MOR. A further increase in catalyst loading is expected to increase the current as in the case of ethanol (experiment not carried out). In the case of ethanol, for the same loading, the current was observed to increase with an increase in rotation. In other words, a threshold thickness/loading can be identified for each alcohol molecule above which the reaction becomes mass transport limited. This threshold thickness value is assumed to be higher for reactive alcohols compared to the less reactive alcohols. Highly reactive molecules (eg: methanol and 2-butanol) could form significant number of intermediates which may cover/block most of the Pt sites and change the Pt surface significantly. At the carbon supported catalyst, the diffusion of soluble products are hindered and the chances of re-adsorption are improved (Scheme 4) as the residence of time of reactive species on the corrugated surface of carbon is higher.

Since a DAFC usually operates on continuous fuel supply mode, not all catalyst particles on the electrode surface may get a uniform fuel concentration and thus the dependence of activity on mass transport has to be considered when designing and optimising the electrode structures [41]. It is significant from the data obtained for $\mathrm{Pt} / \mathrm{C}$ systems that 
the decrease in activity could be compensated by a suitable catalyst design to increase the resident time of the intermediates such as porous carbon supported catalyst and/or porous catalyst structure. Further studies are required to identify the interaction between the intermediates and support, the effect of porous morphology vs. retention time of intermediates etc. to gain more insight into the activity and to design new more effective catalysts for alcohol electro-oxidation reactions.

Acknowledgements The UK Catalysis Hub is kindly thanked for resources and support provided via our membership of the UK Catalysis Hub Consortium and funded by EPSRC (Portfolio Grants. EP/ K014706/2, EP/K014668/1, EP/K014854/1, EP/K014714/1 and EP/ I019693/1).

Open Access This article is distributed under the terms of the Creative Commons Attribution 4.0 International License (http://creativecommons.org/licenses/by/4.0/), which permits unrestricted use, distribution, and reproduction in any medium, provided you give appropriate credit to the original author(s) and the source, provide a link to the Creative Commons license, and indicate if changes were made.

\section{References}

1. Wasmus S, Kuver A (1999) Methanol oxidation and direct methanol fuel cells: a selective review. J Electroanal Chem 461(1-2):14-31

2. Kamarudin MZF, Kamarudin SK, Masdar MS, Daud WRW (2013) Review: direct ethanol fuel cells. Int J Hydrogen Energy 38(22):9438-9453

3. Liu H, Song C, Zhang L, Zhang J, Wang H, Wilkinson DP (2006) A review of anode catalysis in the direct methanol fuel cell. J Power Sources 155(2):95-110

4. Puthiyapura VK, Brett DJL, Russell AE, Lin W-F, Hardacre C (2016) Bio-butanol as fuel for direct alcohol fuel cells-investigation of Sn modified Pt catalyst for butanol electro-oxidation. ACS Appl Mater Interfaces 8(20):12859-12870

5. Puthiyapura VK, Brett DJL, Russell AE, Lin WF, Hardacre C (2015) Development of a ptsn bimetallic catalyst for direct fuel cells using bio-butanol fuel. Chem Commun 51(69):13412-13415

6. Tripkovic AV, Gojkovic SL, Popovic KD, Lovic JD (2006) Methanol oxidation at platinum electrodes in acid solution: comparison between model and real catalysts. J Serb Chem Soc 7(12):1333-1343

7. Iwasita T (2002) Electrocatalysis of methanol oxidation. Electrochim Acta 47(22-23):3663-3674

8. Hamnett A (1997) Mechanism and electrocatalysis in the direct methanol fuel cell. Catal Today 38(4):445-457

9. Liu F, Yan M, Zhou W, Jiang Z (2003) In situ transmission difference FTIR spectroscopic investigation on anodic oxidation of methanol in aqueous solution. Electrochem Commun 5(3):276-282

10. Liang ZX, Zhao TS (2012) Catalysts for alcohol-fuelled direct oxidation fuel cells. RSC energy and environment series, no. 6 . RSC Publishing, Cambridge

11. Kim I, Han OH, Chae SA, Paik Y, Kwon S-H, Lee K-S, Sung Y-E, Kim H (2011) Catalytic reactions in direct ethanol fuel cells. Angew Chem Int Ed 50(10):2270-2274
12. Kavanagh R, Cao X-M, Lin W-F, Hardacre C, Hu P (2012) Origin of low $\mathrm{CO}_{2}$ selectivity on platinum in the direct ethanol fuel cell. Angew Chem Int Ed 51(7):1572-1575

13. Kavanagh R, Cao X-M, Lin W, Hardacre C, Hu P (2012) Acetaldehyde production in the direct ethanol fuel cell: mechanistic elucidation by density functional theory. J Phys Chem C 116(12):7185-7188

14. Lamy C, Belgsir EM, Léger JM (2001) Electrocatalytic oxidation of aliphatic alcohols: application to the direct alcohol fuel cell (DAFC). J Appl Electrochem 31(7):799-809

15. Habibi B, Dadashpour E (2013) Electrooxidation of 2-propanol and 2-butanol on the Pt-Ni alloy nanoparticles in acidic media. Electrochim Acta 88(0):157-164

16. Puthiyapura VK, Brett DJ, Russell AE, Lin WF, Hardacre C (2015) Preliminary investigation on the electrochemical activity of butanol isomers as potential fuel for direct alcohol fuel cell. ECS Trans 69(17):809-816

17. Leung LWH, Weaver MJ (1990) Influence of adsorbed carbon monoxide on electrocatalytic oxidation of simple organic molecules at platinum and palladium electrodes in acidic solution: a survey using real-time FTIR spectroscopy. Langmuir 6(2):323-333

18. Iwasita T, Pastor E (1994) A DEMS and FTIR spectroscopic investigation of adsorbed ethanol on polycrystalline platinum. Electrochim Acta 39(4):531-537

19. Wang H, Baltruschat H (2007) DEMS study on methanol oxidation at poly- and mono-crystalline platinum electrodes: the effect of anion, temperature, surface structure, $\mathrm{Ru}$ adatom, and potential. J Phys Chem C 111(19):7038-7048

20. Wang H, Löffler T, Baltruschat H (2001) Formation of intermediates during methanol oxidation: a quantitative DEMS study. J Appl Electrochem 31(7):759-765

21. Wang H, Wingender C, Baltruschat H, Lopez M, Reetz MT (2001) Methanol oxidation on Pt, PtRu, and colloidal Pt electrocatalysts: a DEMS study of product formation. J Electroanal Chem 509(2):163-169

22. Mostafa E, Abd-El-Latif A-E-AA., Ilsley R, Attard G, Baltruschat H (2012) Quantitative DEMS study of ethanol oxidation: effect of surface structure and Sn surface modification. Phys Chem Chem Phys 14(46):16115-16129

23. Cohen JL, Volpe DJ, Abruna HD (2007) Electrochemical determination of activation energies for methanol oxidation on polycrystalline platinum in acidic and alkaline electrolytes. Phys Chem Chem Phys 9(1):49-77

24. Kutz RB, Braunschweig B, Mukherjee P, Behrens RL, Dlott DD, Wieckowski A (2011) Reaction pathways of ethanol electrooxidation on polycrystalline platinum catalysts in acidic electrolytes. J Catal 278(2):181-188

25. Katikawong P, Ratana T, Veerasai W (2009) Temperature dependence studies on the electro-oxidation of aliphatic alcohols with modified platinum electrodes. J Chem Sci 121(3):329-337

26. Iwasita T, Rasch B, Cattaneo E, Vielstich W (1989) A sniftirs study of ethanol oxidation on platinum. Electrochim Acta 34(8):1073-1079

27. Kim JH, Choi SM, Nam SH, Seo MH, Choi SH, Kim WB (2008) Influence of $\mathrm{Sn}$ content on $\mathrm{PtSn} / \mathrm{C}$ catalysts for electrooxidation of C1-C3 alcohols: synthesis, characterization, and electrocatalytic activity. Appl Catal B-Environ 82(1-2):89-102

28. Vigier F, Coutanceau C, Hahn F, Belgsir EM, Lamy C (2004) On the mechanism of ethanol electro-oxidation on Pt and PtSn catalysts: electrochemical and in situ IR reflectance spectroscopy studies. J Electroanal Chem 563(1):81-89

29. Hayes JR, Zeller D, Friesen C (2008) The influence of platinum surface morphology on the electrooxidation of methanol in alkaline solutions. ECS Trans 13(23):41-54 
30. Bahruji H, Guan S, Puthiyapura VK (2016) Precious metal catalysts for sustainable energy and environmental remediation. In: Modern developments in catalysis. World Scientific, London, pp 211-251

31. Li N-H, Sun S-G, Chen S-P (1997) Studies on the role of oxidation states of the platinum surface in electrocatalytic oxidation of small primary alcohols. J Electroanal Chem 430(1-2):57-67

32. González MJ, Hable CT, Wrighton MS (1998) Electrocatalytic oxidation of small carbohydrate fuels at Pt-Sn modified electrodes. J Phys Chem B 102(49):9881-9890

33. Nan-Hai L, Shi-Gang S (1997) In situ FTIR spectroscopic studies of the electrooxidation of $\mathrm{C} 4$ alcohol on a platinum electrode in acid solutions Part I. Reaction mechanism of 1-butanol oxidation. J Electroanal Chem 436(1-2):65-72

34. Song S, Maragou V, Tsiakaras P (2006) How far are direct alcohol fuel cells from our energy future?. J Fuel Cell Sci Technol 4(2):203-209

35. Iwasita $T$ (2010) Methanol and co electrooxidation. In: Handbook of fuel cells, Wiley, New York

36. Planes GA, García G, Pastor E (2007) High performance mesoporous Pt electrode for methanol electrooxidation. A dems study. Electrochem Commun 9(4):839-844

37. Childers CL, Huang H, Korzeniewski C (1999) Formaldehyde yields from methanol electrochemical oxidation on carbon-supported platinum catalysts. Langmuir 15(3):786-789

38. Seland F, Tunold R, Harrington DA (2010) Activating and deactivating mass transport effects in methanol and formic acid oxidation on platinum electrodes. Electrochim Acta 55(9):3384-3391

39. Seland F, Foss CEL, Tunold R, Harrington D (2010) Increasing and decreasing mass transport effects in the oxidation of small organic molecules. ECS Trans 28(23):203-210

40. Wang H, Jusys Z, Behm RJ (2004) Ethanol electrooxidation on a carbon-supported pt catalyst: reaction kinetics and product yields. J Phys Chem B 108(50):19413-19424

41. Gojković S (2003) Electrochemical oxidation of methanol on Pt3CO bulk alloy. J Serb Chem Soc 68(11):859-870

42. Gojković SaL (2004) Mass transfer effect in electrochemical oxidation of methanol at platinum electrocatalysts. J Electroanal Chem 573(2):271-276

43. Scott K, Taama WM, Argyropoulos P (1998) Material aspects of the liquid feed direct methanol fuel cell. J Appl Electrochem 28(12):1389-1397

44. Darowicki K, Janicka E, Slepski P (2012) Study of direct methanol fuel cell process dynamics using dynamic electrochemical impedance spectroscopy. Int J Electrochem Sci 7(12):12090-12097

45. Seo SH, Lee CS (2008) Effect of operating parameters on the direct methanol fuel cell using air or oxygen as an oxidant gas. Energy Fuels 22(2):1212-1219

46. Katayanagi Y, Yamazaki Y (2010) Effect of fuel flow rate, fuel concentration, and $\mathrm{O}_{2}$ concentration of the cathode gas on the $\mathrm{CO}_{2}$ evolution of a direct ethanol fuel cell. Electrochemistry 78(12):976-981
47. Sayadi A, Pickup PG (2016) Evaluation of methanol oxidation catalysts by rotating disc voltammetry. Electrochim Acta 199:12-17

48. Seidel YE, Schneider A, Jusys Z, Wickman B, Kasemo B, Behm RJ (2010) Transport effects in the electrooxidation of methanol studied on nanostructured Pt/glassy carbon electrodes. Langmuir 26(5):3569-3578

49. Velázquez-Palenzuela A, Centellas F, Garrido JA, Arias C, Rodríguez RM, Brillas E, Cabot P-L (2011) Kinetic analysis of carbon monoxide and methanol oxidation on high performance carbonsupported Pt-Ru electrocatalyst for direct methanol fuel cells. J Power Sources 196(7):3503-3512

50. Bach Delpeuch A, Jacquot M, Chatenet M, Cremers C (2016) The influence of mass-transport conditions on the ethanol oxidation reaction (EOR) mechanism of $\mathrm{Pt} / \mathrm{C}$ electrocatalysts. Phys Chem Chem Phys 18(36):25169-25175

51. Sayadi A, Pickup PG (2016) Evaluation of ethanol oxidation catalysts by rotating disc voltammetry. Electrochim Acta 215:84-92

52. Hou G, Parrondo J, Ramani V, Prakash J (2014) Kinetic and mechanistic investigation of methanol oxidation on a smooth polycrystalline Pt surface. J Electrochem Soc 161(3):F252-F258

53. Lim D-H, Choi D-H, Lee W-D, Lee H-I (2009) A new synthesis of a highly dispersed and co tolerant $\mathrm{PtSn} / \mathrm{C}$ electrocatalyst for low-temperature fuel cell; its electrocatalytic activity and longterm durability. Appl Catal B-Environ 89(3-4):484-493

54. Camara GA, Iwasita $T$ (2005) Parallel pathways of ethanol oxidation: the effect of ethanol concentration. J Electroanal Chem 578(2):315-321

55. Colmenares L, Wang H, Jusys Z, Jiang L, Yan S, Sun GQ, Behm RJ (2006) Ethanol oxidation on novel, carbon supported Pt alloy catalysts - model studies under defined diffusion conditions. Electrochim Acta 52(1):221-233

56. Shin J, Tornquist WJ, Korzeniewski C, Hoaglund CS (1996) Elementary steps in the oxidation and dissociative chemisorption of ethanol on smooth and stepped surface planes of platinum electrodes. Surf Sci 364(2):122-130

57. Hofstead-Duffy AM, Chen D-J, Sun S-G, Tong YJ (2012) Origin of the current peak of negative scan in the cyclic voltammetry of methanol electro-oxidation on Pt-based electrocatalysts: a revisit to the current ratio criterion. J Mater Chem 22(11):5205-5208

58. Mukherjee P, Bhattacharya S (2014) Anodic oxidation of butan1-ol on Pd and Pt electrodes in alkaline medium. J Appl Electrochem 44(7):857-866

59. Gootzen JFE, Wonders AH, Visscher W, van Veen JAR (1997) Adsorption of C3 alcohols, 1-butanol, and ethene on platinized platinum as studied with FTIRS and DEMS. Langmuir 13(6):1659-1667

60. Pastor E, González S, Arvia AJ (1995) Electroreactivity of isopropanol on platinum in acids studied by DEMS and FTIRS. J Electroanal Chem 395(1-2):233-242

61. Zhang J, Liu P, Ma H, Ding Y (2007) Nanostructured porous gold for methanol electro-oxidation. J Phys Chem C 111(28):10382-10388 